\title{
Molecular detection of lymph node metastasis in breast cancer patients treated with preoperative systemic chemotherapy: a prospective multicentre trial using the one-step nucleic acid amplification assay
}

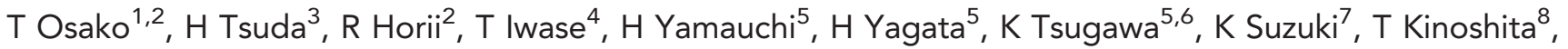
F Akiyama*,1 and S Nakamura ${ }^{5,9}$

${ }^{1}$ Division of Pathology, The Cancer Institute of Japanese Foundation for Cancer Research, Tokyo, Japan; ${ }^{2}$ Department of Pathology, The Cancer Institute Hospital of Japanese Foundation for Cancer Research, Tokyo, Japan; ${ }^{3}$ Department of Pathology and Clinical Laboratories, National Cancer Center Hospital, Tokyo, Japan; ${ }^{4}$ Breast Oncology Center, The Cancer Institute Hospital of Japanese Foundation for Cancer Research, Tokyo, Japan; ${ }^{5}$ Department of Breast Surgical Oncology, St Luke's International Hospital, Tokyo, Japan; ${ }^{6}$ Division of Breast and Endocrine Surgery, St Marianna University School of Medicine, Kanagawa, Japan; ${ }^{7}$ Department of Diagnostic Pathology, St Luke's International Hospital, Tokyo, Japan; ${ }^{8}$ Breast Surgery Division, National Cancer Center Hospital, Tokyo, Japan and ${ }^{9}$ Department of Surgery, Division of Breast Surgical Oncology, Showa University School of Medicine, Tokyo, Japan

Background: For patients with breast cancer treated with preoperative chemotherapy, residual tumour burden in lymph nodes is the strongest prognostic factor. However, conventional pathological examination has limitations that hinder the accurate and reproducible measurement. The one-step nucleic acid amplification (OSNA) assay is a novel molecular method for detecting nodal metastasis. In this prospective multicentre trial, we assessed the performance of the OSNA assay in detecting nodal metastasis after chemotherapy.

Methods: In total, 302 lymph nodes from 80 breast cancer patients who underwent axillary dissection after chemotherapy were analysed. Each node was cut into two or four slices. One piece or alternate pieces were evaluated by pathology, and the other(s) were examined using the OSNA assay. The results of the two methods were compared. Stromal fibrosis, histiocytic aggregates, and degenerated cancer cells were regarded as chemotherapy-induced histological changes.

Results: The overall accuracy, sensitivity, and specificity of the OSNA assay compared with the reference pathology were 91.1\%, $88.3 \%$, and $91.7 \%$, respectively. Of the 302 lymph nodes, 66 (21.9\%) exhibited chemotherapy-induced histology. For these nodes, the accuracy, sensitivity, and specificity were $90.9 \%, 88.9 \%$, and $93.3 \%$, respectively.

Conclusion: The OSNA assay can detect the residual tumour burden as accurately as conventional pathology, although chemotherapy-induced histological changes are present. 
Preoperative systemic chemotherapy, initially used only for inflammatory and inoperable locally advanced breast cancer, has recently been more widely used for operable disease (Kaufmann et al, 2006; Gralow et al, 2008). Although systemic chemotherapy before and after surgery results in identical survival rates, preoperative chemotherapy has the advantages of eliciting a tumour response in individual patients and increasing the number of patients eligible for breast-conserving surgery (Kaufmann et al, 2006; Gralow et al, 2008). The residual tumour burden in the breast and axillary lymph node after preoperative chemotherapy is the strongest prognostic factor (Carey et al, 2005; von Minckwitz et al, 2012). Moreover, the residual tumour burden in the axillary node is a better prognostic factor than the response of the primary tumour (Rouzier et al, 2002; von Minckwitz et al, 2012), and residual micrometastatic disease is predictive of poor prognosis (Fisher et al, 2002; Klauber-DeMore et al, 2006; Sakakibara et al, 2009). Thus, accurate evaluation of axillary node status is of great clinical significance in patients with breast cancer who are treated with preoperative chemotherapy.

Conventional pathological examination of lymph nodes has three potential limitations that affect the accurate and reproducible measurement of the total residual metastatic volume. First, pathological examinations only partially evaluate each node, and this may lead to underestimation of the nodal status. Although underestimation of the metastasis volume can be reduced by serial sectioning, this imposes a heavy workload for pathologists. Second, histological changes caused by chemotherapy, such as decreases in cellularity with stromal fibrosis, aggregates of foamy histiocytes, and degenerated cancer cells, can affect tumour burden assessment (Sahoo and Lester, 2009). Finally, the practice of pathological evaluation of lymph nodes is not standardised. Examination protocols vary from one institution to another (Cserni et al, 2004), and there is inter-observer variability in diagnosing the tumour burden, particularly for low-volume metastasis (Cserni et al, 2008).

The one-step nucleic acid amplification (OSNA) assay is a novel molecular method for the lymph node staging of breast cancer (Tsujimoto et al, 2007) that has been tested in multiple series (Cserni, 2012; Tamaki, 2012). The results of this semi-automated molecular assay based on the quantification of cytokeratin 19 (CK19) mRNA display a 96\% concordance rate with detailed pathology complemented by immunohistochemistry when alternate slices of the same lymph node are used for the two tests (Cserni, 2012; Tamaki, 2012). The OSNA assay is accepted and routinely used in $>230$ institutions in Spain, Japan, Italy, the UK, France, and other countries (http://lifescience.sysmex.co.jp/ls/ products/osna/index.html). However, the performance of the OSNA assay has not been evaluated in patients treated with preoperative systemic therapy. This assay can potentially contribute to the accurate, reproducible, and standardised evaluation of the lymph node status after systemic therapy. In this prospective multicentre trial, we compared the performance of the OSNA assay with that of pathological examination and investigated the effect of chemotherapy-induced histological changes on its performance.

\section{MATERIALS AND METHODS}

Enrolled patients and lymph nodes. Axillary lymph nodes were obtained from patients with breast cancer who underwent standard preoperative chemotherapy followed by axillary lymph node dissection between May 2010 and March 2011 at one of three Japanese institutions. This study was approved by the ethics committee of each institution. Patients were given the necessary written information about the study, and only the lymph nodes from patients who gave their consent were included in the analysis.
A maximum of four lymph nodes sampled from the level-I axillary region were included for a single patient. The remaining nodes were evaluated by permanent histology using singlesectioned nodes. The clinical and pathological TNM classification and staging and the level of axillary lymph node dissection of each patient were classified according to the seventh edition of the American Joint Committee on Cancer Staging Manual (Edge et al, 2010).

Lymph node examination process. Sampled fresh lymph nodes larger than $4 \mathrm{~mm}$ in short axis were immediately sliced using the cutting device developed by Tsujimoto et al (2007), resulting in two $2-\mathrm{mm}$ central sections (i.e., sections $\mathrm{b}$ and $\mathrm{c}$ ) with additional two excess sections on both sides (i.e., sections a and d; Figure 1A). Alternate pieces (i.e., sections a and c) were evaluated by two-level pathological examination, and the others (i.e., sections $b$ and $d$ ) were examined using the OSNA assay. Lymph nodes sized $4 \mathrm{~mm}$ or less in short axis were cut by the cutting device into two pieces (Figure 1B). One piece (i.e., section a') was evaluated by pathological examination, and the other piece (i.e., section b') was examined using the OSNA assay. The lymph node slices for pathological examination were fixed with formalin and embedded in paraffin, and the slices for the OSNA assay were stored frozen at $-80{ }^{\circ} \mathrm{C}$ until measurement.

Pathological examination. A pair of $4-\mu \mathrm{m}$-thick sections was prepared from each slice (Figure 1): one section was stained with haematoxylin-and-eosin and the other was immunostained with a CK19 antibody (Clone RCK108; Dako, Glostrup, Denmark). All slides were centrally reviewed by one experienced pathologist $(\mathrm{RH})$ who was blinded to the results of the OSNA assay. Each node was classified as having macrometastasis ( $>2.0 \mathrm{~mm}$ in size), micrometastasis $(>0.2-2.0 \mathrm{~mm}$ in size), isolated tumour cells (ITC, $\leqslant 0.2 \mathrm{~mm}$ in size), or no cancer cells according to the seventh edition of the American Joint Committee on Cancer classification (Edge et al, 2010). Macrometastasis and micrometastasis were regarded as positive findings, and ITCs and no cancer cells were regarded as negative findings. Furthermore, stromal fibrosis, aggregates of foamy histiocytes, and degenerated cancer cells in lymph nodes were regarded as chemotherapy-induced histological changes.

The OSNA assay. The procedure for the OSNA assay has been previously described in detail (Tsujimoto et al, 2007). Briefly, frozen slices of lymph nodes were homogenised with $4 \mathrm{ml}$ of lysis buffer solution (Lynorhag; Sysmex Corporation, Kobe, Japan) and

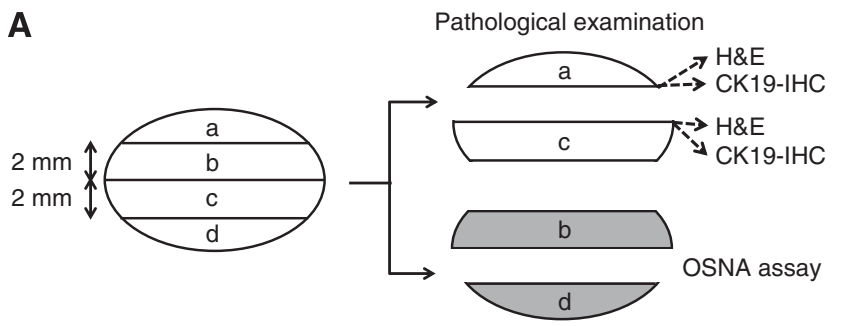

B

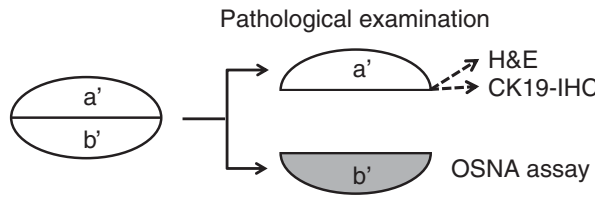

Figure 1. Lymph node examination process. Lymph nodes larger than $4 \mathrm{~mm}$ were sliced into four pieces (A), and lymph nodes sized $4 \mathrm{~mm}$ or less were cut into two pieces (B). H\&E, haematoxylin-and-eosin staining; CK19-IHC, cytokeratin 19 immunohistochemistry; OSNA, one-step nucleic acid amplification. 
centrifuged at $10000 \mathrm{~g}$ at room temperature. Two microlitres of supernatant was analysed using the RD-100i System (Sysmex Corporation), an automated molecular detection system that uses a reverse transcription loop-mediated isothermal amplification method (Notomi et al, 2000), and the LynoampBC Kit (Sysmex Corporation). The degree of amplification was determined on the basis of a reaction by-product, pyrophosphate (Mori et al, 2001). The resultant change in turbidity on the precipitation of magnesium pyrophosphate was then correlated with the CK19 mRNA copy number per microlitre of the original lysate via a standard curve established beforehand using three calibrators containing different CK19 mRNA copy numbers. The number of CK19 mRNA copies per microlitre was extrapolated from the standard curve for both the measurement sample and a $1: 10$ diluted sample. The cutoffs for negative/positive results and $(+) /(++)$ were set at 250 and 5000 copies per microlitre, respectively (Tsujimoto et al, 2007). Positive $(+)$ was considered equivalent to micrometastasis (not including ITC), and positive $(++)$ was considered equivalent to macrometastasis (Tsujimoto et al, 2007). In situations in which the reaction was inhibited in the measurement sample, the copy numbers in the diluted sample were used.

Additional investigation of discordant lymph nodes. For lymph nodes that were positive on the OSNA assay and negative (no cancer cells) on pathological examination, the paraffin blocks of the lymph node tissue were step-sectioned with $0.2-\mathrm{mm}$ intervals until the tissue was exhausted. At each level, two microscopic slides were made: one was used for haematoxylinand-eosin staining and the other was used for CK19 immunostaining. All stained slides were microscopically examined by the central pathologist $(\mathrm{RH})$.

Statistical analysis. With the result of the pathological examination as the gold standard, the accuracy, sensitivity, and specificity of the OSNA assay were calculated. The differences in the accuracy, sensitivity, and specificity between lymph nodes with and without chemotherapy-induced histological changes were assessed by the two-population $z$-test. Confidence intervals (CIs) were set at the $95 \%$ level. $P$-values of $<0.05$ were considered statistically significant. All statistical analyses were performed using $\mathrm{R}$ statistical software (version 2.10.1, http://www.r-project.org/; Ihaka and Gentleman, 1996).

\section{RESULTS}

Enrolled patients and lymph nodes. In total, 307 lymph nodes obtained from 80 patients who underwent surgery after preoperative chemotherapy were included in the study. Of these, four nodes were excluded because of a lack of lymph node tissue, and one node was excluded because it was not subjected to the OSNA assay. Thus, 302 nodes from 80 patients were included in the analysis. The characteristics of the 80 patients are shown in Table 1 . Of the 80 patients, 71 (88.8\%) were diagnosed with nodepositive before receiving chemotherapy. Of the 71 patients, 8,52 , and 11 were confirmed as positive by sentinel node biopsy, fine needle aspiration cytology, and clinical examination/imaging, respectively. The mean and median numbers of enrolled lymph nodes included from a single patient were 3.8 and 4 , respectively. Of the 302 nodes, 192 nodes (63.6\%) were sliced into four pieces, and 110 nodes $(36.4 \%)$ were cut into two pieces.

Overall performance of the OSNA assay. The results of the pathological examination and the OSNA assay were concordant for 275 of 302 nodes (accuracy, 91.1\%; 95\% CI, 87.3-94.0\%; Table 2). Of the 60 nodes identified as positive for metastasis on pathological examination, 53 nodes were identified as positive on the OSNA
Table 1. Patient characteristics

\begin{tabular}{|l|c|c|}
\hline Characteristics & No. & $\%$ \\
\hline No. of patients & 80 & $100.0 \%$ \\
\hline
\end{tabular}

Age (years)

\begin{tabular}{|l|l|}
\hline Median (range) & 52 (30-71)
\end{tabular}

Clinical $\mathrm{N}$ status before chemotherapy

\begin{tabular}{|c|c|c|}
\hline cN0 & 9 & $11.3 \%$ \\
cN1 & 59 & $73.8 \%$ \\
cN2 & 2 & $2.5 \%$ \\
cN3 & 10 & $12.5 \%$ \\
\hline
\end{tabular}

Clinical stage before chemotherapy

\begin{tabular}{|l|c|c|}
\hline IIA & 15 & $18.8 \%$ \\
IIB & 39 & $48.8 \%$ \\
IIIA & 12 & $15.0 \%$ \\
IIIB & 3 & $3.8 \%$ \\
IIIC & 9 & $11.3 \%$ \\
IV & 2 & $2.5 \%$ \\
\hline
\end{tabular}

Histological type

Invasive ductal

Invasive micropapillary

$97.5 \%$

$2.5 \%$

Oestrogen receptor status

\begin{tabular}{|l|l|l|}
\hline- & 25 & $31.3 \%$ \\
+ & 55 & $68.8 \%$ \\
\hline
\end{tabular}

Progesterone receptor status

\begin{tabular}{|l|l|l|}
\hline- & 38 & $47.5 \%$ \\
+ & 42 & $52.5 \%$ \\
\hline
\end{tabular}

HER2 status

\begin{tabular}{|l|c|c|}
\hline- & 54 & $67.5 \%$ \\
+ & 18 & $22.5 \%$ \\
Uncertain & 8 & $10.0 \%$ \\
\hline
\end{tabular}

Chemotherapy regimen

\begin{tabular}{|l|c|c|}
\hline Anthracycline & 4 & $5.0 \%$
\end{tabular}

Anthracycline/taxane

Anthracycline/taxane/carboplatin

Anthracycline/taxane/trastuzumab

Taxane

Taxane/trastuzumab

$62.5 \%$

$3.8 \%$

$18.8 \%$

$8.8 \%$

$1.3 \%$

Breast surgery

Total mastectomy

Partial mastectomy

47
33

$58.8 \%$

\begin{tabular}{l|l|l} 
Partial mastectomy & 33 & $41.3 \%$
\end{tabular}

Axillary lymph node dissection

\begin{tabular}{|l|c|c|}
\hline Level I & 1 & $1.3 \%$ \\
Level II & 70 & $87.5 \%$ \\
Level III & 9 & $11.3 \%$ \\
\hline
\end{tabular}

No. of lymph nodes removed

\begin{tabular}{|l|l|}
\hline Median (range) & $16(5-38)$
\end{tabular}

Pathological T status after chemotherapy

\begin{tabular}{|l|r|}
\hline ypT0 & 10 \\
ypTis & 21 \\
ypT1 & 20 \\
ypT2 & 21 \\
ypT3 &
\end{tabular}

Pathological $\mathrm{N}$ status after chemotherapy 
assay (sensitivity, $88.3 \%$; 95\% CI, 77.4-95.2\%). Of the 242 nodes identified as negative for metastasis on pathological examination, 222 nodes were identified as negative on the OSNA assay (specificity, 91.7\%; 95\% CI, 87.5-94.9\%).

Chemotherapy-induced histological changes and performance of the OSNA assay. Of the 302 lymph nodes, 66 (21.9\%) displayed chemotherapy-induced histological changes. The accuracy, sensitivity, and specificity of the OSNA assay relative to the reference pathology were $90.9 \%$ (60 out of 66 ), $88.9 \%$ (32 out of 36 ), and $93.3 \%$ (28 out of 30 ), respectively, among lymph nodes with chemotherapy-induced histological changes and $91.1 \%$ (215 out of 236), $87.5 \%$ (21 out of 24), and $91.5 \%$ (194 out of 212), respectively, among lymph nodes without histological changes (Table 3). There were no differences in accuracy, sensitivity, or specificity between the two groups $(P=0.96,0.87$, and 0.73 , respectively).

Lymph nodes with discordant results. Of the 302 lymph nodes, $27(8.9 \%)$ showed discordant results between the pathological examination and the OSNA assay (Table 4). Of these 27 nodes, 20 were negative on pathological examination and positive on the OSNA assay (false positive when using pathology as the gold standard), whereas 7 were positive on pathological examination

Table 2. Comparison of the results of the OSNA assay with pathological examination

\begin{tabular}{|l|c|c|c|c|}
\cline { 2 - 5 } \multicolumn{1}{|c|}{} & \multicolumn{3}{c|}{ Pathology } \\
\cline { 2 - 5 } & \multicolumn{3}{|c|}{ Positive } & Negative \\
\cline { 2 - 5 } & Macro & Micro & ITC & None \\
\hline OSNA & 32 & 3 & 2 & 4 \\
\hline Positive & 10 & 8 & 3 & 11 \\
\hline $\begin{array}{l}(++) \\
(+)\end{array}$ & 1 & 6 & 1 & 221 \\
\hline Negative & & & \\
\hline Abbreviations: ITC $=$ isolated tumour cells; OSNA = one-step nucleic acid amplification. \\
\hline
\end{tabular}

and negative on the OSNA assay (false negative when using pathology as the gold standard).

Of the 20 nodes with false-positive results, ITCs were identified in five nodes during the original pathological assessment. Moreover, cancer cells were identified in two nodes (one with micrometastasis and one with ITC) during the additional pathological assessment. In contrast, no cancer cells were identified in 13 nodes during the additional pathological examination; the median CK19 mRNA copy number was 450 (range, 280-250 000).

Of the seven nodes with false-negative results, six nodes displayed micrometastasis and one node exhibited macrometastasis. The median size of metastasis on pathology was $0.8 \mathrm{~mm}$ (range, $>0.2-12.0 \mathrm{~mm}$ ). In all seven nodes, CK19 protein expression was detected by immunohistochemistry.

\section{DISCUSSION}

To the best of our knowledge, this prospective multicentre trial is the first study to evaluate the performance of a molecular assay in detecting lymph node metastasis in patients with breast cancer who were treated with preoperative systemic therapy. The OSNA assay can detect the residual tumour burden in lymph nodes after chemotherapy as accurately as conventional pathology. The overall performance of the OSNA assay in this study is almost equivalent to the results of two pooled analyses of previous trials in which similar protocols were used in patients who did not receive preoperative systemic therapy (accuracy, 93.6-96.1\%; sensitivity, 87.9-91.7\%; specificity, 94.8-97.0\%; Cserni, 2012; Tamaki, 2012). Moreover, chemotherapy-induced histological changes did not affect the performance of the OSNA assay. The performance of the assay for lymph nodes with chemotherapy-induced histological changes was similar to that for lymph nodes without histological changes as well as that reported in the aforementioned pooled analyses.

The main reason for the discordant results between the OSNA assay and conventional pathology may be tissue allocation bias. As per the protocol of this study, small metastases localised in only one slice inevitably result in discordant findings. Of the 20 nodes displaying false-positive results, 7 nodes showed cancer cells on the original or additional pathological assessment slides. In addition, 10 nodes had a low tumour burden of no $>1000$ copies. Thus, in

Table 3. Chemotherapy-induced histological changes and performance of the OSNA assay

\begin{tabular}{|c|c|c|c|c|c|c|c|c|}
\hline & \multicolumn{8}{|c|}{ Pathology } \\
\hline & \multicolumn{4}{|c|}{ Presence of histological changes $(n=66)$} & \multicolumn{4}{|c|}{ Absence of histological changes $(n=236)$} \\
\hline & \multicolumn{2}{|c|}{ Positive } & \multicolumn{2}{|c|}{ Negative } & \multicolumn{2}{|c|}{ Positive } & \multicolumn{2}{|c|}{ Negative } \\
\hline & Macro & Micro & ITC & None & Macro & Micro & ITC & None \\
\hline \multicolumn{9}{|l|}{ OSNA } \\
\hline \multicolumn{9}{|l|}{ Positive } \\
\hline $\begin{array}{l}(++) \\
(+)\end{array}$ & $\begin{array}{r}17 \\
8\end{array}$ & $\begin{array}{l}1 \\
6\end{array}$ & $\begin{array}{l}1 \\
1\end{array}$ & $\begin{array}{l}0 \\
0\end{array}$ & $\begin{array}{r}15 \\
2\end{array}$ & $\begin{array}{l}2 \\
2\end{array}$ & $\begin{array}{l}1 \\
2\end{array}$ & $\begin{array}{r}4 \\
11\end{array}$ \\
\hline Negative & 0 & 4 & 0 & 28 & 1 & 2 & 1 & 193 \\
\hline Accuracy $(95 \% \mathrm{Cl})$ & \multicolumn{4}{|c|}{$90.9 \%(0.81-0.97)$} & \multicolumn{4}{|c|}{$91.1 \%(0.87-0.94)$} \\
\hline Sensitivity $(95 \% \mathrm{Cl})$ & \multicolumn{4}{|c|}{$88.9 \%(0.74-0.97)$} & \multicolumn{4}{|c|}{$87.5 \%(0.68-0.97)$} \\
\hline Specificity $(95 \% \mathrm{Cl})$ & \multicolumn{4}{|c|}{$93.3 \%(0.78-0.99)$} & \multicolumn{4}{|c|}{$91.5 \%(0.87-0.95)$} \\
\hline
\end{tabular}


Table 4. Lymph nodes with discordant results and the possible cause

\begin{tabular}{|c|c|c|c|c|c|c|}
\hline & \multicolumn{2}{|c|}{ OSNA } & \multicolumn{3}{|c|}{ Pathology } & \multirow[b]{2}{*}{ Possible cause } \\
\hline Lymph node & Result & $\begin{array}{c}\text { CK19 mRNA } \\
\left(\text { copy } \mu l^{-1}\right)\end{array}$ & $\begin{array}{c}\text { Original assessment } \\
\text { (size, } \mathrm{mm})\end{array}$ & $\begin{array}{c}\text { Additional } \\
\text { assessment (size, } \mathrm{mm})\end{array}$ & CK19 protein & \\
\hline \multicolumn{7}{|l|}{ False positive } \\
\hline $\begin{array}{l}\text { JC28-4 } \\
\text { SL07-4 } \\
\text { CR02-3 } \\
\text { JC07-4 } \\
\text { JC26-4 } \\
\text { SL02-4 } \\
\text { CR02-2 } \\
\text { SL07-2 } \\
\text { SL12-4 } \\
\text { CR17-4 } \\
\text { JC11-4 } \\
\text { CR07-2 } \\
\text { JC18-1 } \\
\text { SL06-4 } \\
\text { CR13-3 } \\
\text { JC10-2 } \\
\text { SL09-1 } \\
\text { SL14-1 } \\
\text { SL06-1 } \\
\text { SL13-2 }\end{array}$ & $\begin{array}{c}(++) \\
(++) \\
(+) \\
(+) \\
(+) \\
(+) \\
(++) \\
(++) \\
(++) \\
(++) \\
(+) \\
(+) \\
(+) \\
(+) \\
(+) \\
(+) \\
(+) \\
(+) \\
(+) \\
(+)\end{array}$ & $\begin{array}{r}32000 \\
6300 \\
2300 \\
460 \\
300 \\
280 \\
13000 \\
250000 \\
6300^{\mathrm{a}} \\
5600 \\
1000 \\
960 \\
710^{\mathrm{a}} \\
450^{\mathrm{a}} \\
410 \\
400 \\
400 \\
330 \\
300 \\
280\end{array}$ & $\begin{array}{c}\text { ITC }(\leqslant 0.2) \\
\text { ITC }(\leqslant 0.2) \\
\text { ITC }(\leqslant 0.2) \\
\text { ITC }(\leqslant 0.2) \\
\text { ITC }(\leqslant 0.2) \\
\text { None } \\
\text { None } \\
\text { None } \\
\text { None } \\
\text { None } \\
\text { None } \\
\text { None } \\
\text { None } \\
\text { None } \\
\text { None } \\
\text { None } \\
\text { None } \\
\text { None } \\
\text { None } \\
\text { None }\end{array}$ & $\begin{array}{l}\text { NA } \\
\text { NA } \\
\text { NA } \\
\text { NA } \\
\text { NA } \\
\text { Micro }(0.8) \\
\text { ITC }(\leqslant 0.2) \\
\text { None } \\
\text { None } \\
\text { None } \\
\text { None } \\
\text { None } \\
\text { None } \\
\text { None } \\
\text { None } \\
\text { None } \\
\text { None } \\
\text { None } \\
\text { None } \\
\text { None }\end{array}$ & $\begin{array}{l}(+) \\
(+) \\
(+) \\
(+) \\
(+) \\
(+) \\
(+) \\
\text { NA } \\
\text { NA } \\
\text { NA } \\
\text { NA } \\
\text { NA } \\
\text { NA } \\
\text { NA } \\
\text { NA } \\
\text { NA } \\
\text { NA } \\
\text { NA } \\
\text { NA } \\
\text { NA }\end{array}$ & $\begin{array}{l}\text { Allocation bias } \\
\text { Allocation bias } \\
\text { Allocation bias } \\
\text { Allocation bias } \\
\text { Allocation bias } \\
\text { Allocation bias } \\
\text { Allocation bias } \\
\text { Human error } \\
\text { Allocation bias } \\
\text { Allocation bias } \\
\text { Allocation bias } \\
\text { Allocation bias } \\
\text { Allocation bias } \\
\text { Allocation bias } \\
\text { Allocation bias } \\
\text { Allocation bias } \\
\text { Allocation bias } \\
\text { Allocation bias } \\
\text { Allocation bias } \\
\text { Allocation bias }\end{array}$ \\
\hline \multicolumn{7}{|c|}{ False negative } \\
\hline $\begin{array}{l}\text { SL07-3 } \\
\text { JC19-2 } \\
\text { JC35-2 } \\
\text { SL09-4 } \\
\text { JC21-1 } \\
\text { JC04-3 } \\
\text { JC21-3 }\end{array}$ & $\begin{array}{l}(-) \\
(-) \\
(-) \\
(-) \\
(-) \\
(-) \\
(-)\end{array}$ & $\begin{array}{l}<250 \\
N D \\
N D \\
<250 \\
N D \\
<250 \\
N D\end{array}$ & $\begin{array}{l}\text { Macro }(12.0) \\
\text { Micro }(1.0) \\
\text { Micro }(1.0) \\
\text { Micro }(0.8) \\
\text { Micro }(0.8) \\
\text { Micro }(0.5) \\
\text { Micro }\left(0.2^{b}\right)\end{array}$ & $\begin{array}{l}\text { NA } \\
\text { NA } \\
\text { NA } \\
\text { NA } \\
\text { NA } \\
\text { NA } \\
\text { NA }\end{array}$ & $\begin{array}{l}(+) \\
(+) \\
(+) \\
(+) \\
(+) \\
(+) \\
(+)\end{array}$ & $\begin{array}{l}\text { Human error } \\
\text { Allocation bias } \\
\text { Allocation bias } \\
\text { Allocation bias } \\
\text { Allocation bias } \\
\text { Allocation bias } \\
\text { Allocation bias }\end{array}$ \\
\hline $\begin{array}{l}\text { Abbreviations: CK1 } \\
{ }^{\text {a }} \text { CK19 mRNA copy } \\
\text { b }_{\text {Just over } 0.2 \mathrm{~mm}}\end{array}$ & $\begin{array}{l}\text { n 19; } 17 \\
\text { he dilu }\end{array}$ & d tumour cells; $\uparrow$ & tt available; ND = not de & OSNA = one-step nucleic a & lification. & \\
\hline
\end{tabular}

these 17 nodes, tissue allocation bias could have resulted in discordant findings. In addition, two nodes (\#SL12-4 and \#CR17-4) had metastasis with 5000-6000 copies; these copy numbers suggest that the tumours are approximately $2 \mathrm{~mm}$ in size (Tsujimoto et al, 2007). Although the metastatic status of these two nodes is indeterminate, tissue allocation bias is also suspected as the cause of the discordant results. Furthermore, all seven nodes with false-negative results were positive for CK19 protein expression. Although the OSNA assay may miss metastases that do not express CK19 mRNA in principle, the false-negative results in this study did not appear to be caused by the absence or low expression of CK19 mRNA. Of the seven nodes, six had micrometastasis of $\leqslant 1.0 \mathrm{~mm}$ in size. Therefore, tissue allocation bias is a possible cause of the discordant results for these six nodes.

The discordant results of the remaining two nodes (\#SL07-2 and \#SL07-3) may be due to human error. In lymph node \#SL07-2, the CK19 mRNA copy number was high, but no cancer cells were detected during the original or additional pathological examination. In contrast, in lymph node \#SL07-3, the CK19 mRNA copy number was low, whereas a large metastatic lesion expressing CK19 was observed during the pathological examination. Lymph nodes \#SL07-2 and \#SL07-3 were sampled from the same patient. Therefore, the pieces for the OSNA assay or the pathological samples of the two nodes may have been switched during the handling of the samples.
In clinical practice, the OSNA assay can contribute to the accurate, reproducible, and standardised evaluation of the residual tumour burden after preoperative chemotherapy. When a whole lymph node or a large amount of a node is examined using the OSNA assay, more micrometastases can be detected than by the use of routine pathological examinations (Osako et al, 2011a,b, 2012; Remoundos et al, 2013). This is reasonable considering that routine pathology analyses only limited a part of the lymph node, whereas the OSNA assay can thoroughly evaluate the entire lymph node. Patients with negative nodes or micrometastases who were not treated with preoperative chemotherapy had identical survival rates, whereas the survival rate of patients with micrometastases in lymph nodes after chemotherapy was similar to that of patients with macrometastases and significantly worse than that of patients with negative nodes (Fisher et al, 2002). Thus, the OSNA assay facilitates prediction of the prognosis of patients treated with preoperative chemotherapy more accurately than conventional pathological examinations. Although further chemotherapy may potentially not be delivered after neoadjuvant chemotherapy plus surgery, adjuvant therapies including radiation, hormone, and molecular-target therapies can be considered for these patients. Therefore, this more accurate diagnosis of lymph node status can enable to personalise the adjuvant therapy for each of the patients.

In conclusion, the OSNA assay can detect residual tumour burden in lymph nodes after chemotherapy as accurately as 
conventional pathology even when chemotherapy-induced histological changes are present. The main cause of discordant results may be tissue allocation bias. Therefore, the OSNA assay can contribute to the accurate, reproducible, and standardised evaluation of lymph node status after preoperative chemotherapy.

\section{ACKNOWLEDGEMENTS}

We thank all of the staff of the clinical and pathological laboratories at the participating institutions. This study was funded by Sysmex Corporation.

\section{REFERENCES}

Carey LA, Metzger R, Dees EC, Collichio F, Sartor CI, Ollila DW, KlauberDeMore N, Halle J, Sawyer L, Moore DT, Graham ML (2005) American Joint Committee on Cancer tumor-node-metastasis stage after neoadjuvant chemotherapy and breast cancer outcome. J Natl Cancer Inst 97(15): 1137-1142.

Cserni G (2012) Intraoperative analysis of sentinel lymph nodes in breast cancer by one-step nucleic acid amplification. J Clin Pathol 65(3): 193-199.

Cserni G, Amendoeira I, Apostolikas N, Bellocq JP, Bianchi S, Boecker W, Borisch B, Connolly CE, Decker T, Dervan P, Drijkoningen M, Ellis IO, Elston CW, Eusebi V, Faverly D, Heikkila P, Holland R, Kerner H, Kulka J, Jacquemier J, Lacerda M, Martinez-Penuela J, De Miguel C, Peterse JL, Rank F, Regitnig P, Reiner A, Sapino A, Sigal-Zafrani B, Tanous AM, Thorstenson S, Zozaya E, Fejes G, Wells CA (2004) Discrepancies in current practice of pathological evaluation of sentinel lymph nodes in breast cancer. Results of a questionnaire based survey by the European Working Group for Breast Screening Pathology. J Clin Pathol 57(7): 695-701.

Cserni G, Bianchi S, Vezzosi V, van Diest P, van Deurzen C, Sejben I, Regitnig P, Asslaber M, Foschini MP, Sapino A, Castellano I, Callagy G, Arkoumani E, Kulka J, Wells CA (2008) Variations in sentinel node isolated tumour cells/micrometastasis and non-sentinel node involvement rates according to different interpretations of the TNM definitions. Eur J Cancer 44(15): $2185-2191$.

Edge SB, Byrd DR, Compton CC, Fritz AG, Greene FL, Trotti A (2010) American Joint Committee on Cancer Cancer Staging Manual, 7th edn. Springer: New York, NY, USA.

Fisher ER, Wang J, Bryant J, Fisher B, Mamounas E, Wolmark N (2002) Pathobiology of preoperative chemotherapy: findings from the National Surgical Adjuvant Breast and Bowel (NSABP) protocol B-18. Cancer 95(4): 681-695

Gralow JR, Burstein HJ, Wood W, Hortobagyi GN, Gianni L, von Minckwitz G, Buzdar AU, Smith IE, Symmans WF, Singh B, Winer EP (2008) Preoperative therapy in invasive breast cancer: pathologic assessment and systemic therapy issues in operable disease. J Clin Oncol 26(5): 814-819.

Ihaka R, Gentleman R (1996) R: a language for data analysis and graphics. J Comp Graph Stat 5: 299-314.

Kaufmann M, Hortobagyi GN, Goldhirsch A, Scholl S, Makris A, Valagussa P, Blohmer JU, Eiermann W, Jackesz R, Jonat W, Lebeau A, Loibl S, Miller W, Seeber S, Semiglazov V, Smith R, Souchon R, Stearns V, Untch M, von Minckwitz G (2006) Recommendations from an international expert panel on the use of neoadjuvant (primary) systemic treatment of operable breast cancer: an update. J Clin Oncol 24(12): 1940-1949.

Klauber-DeMore N, Ollila DW, Moore DT, Livasy C, Calvo BF, Kim HJ, Dees EC, Sartor CI, Sawyer LR, Graham 2nd M, Carey LA (2006) Size of residual lymph node metastasis after neoadjuvant chemotherapy in locally advanced breast cancer patients is prognostic. Ann Surg Oncol 13(5): 685-691.

Mori Y, Nagamine K, Tomita N, Notomi T (2001) Detection of loop-mediated isothermal amplification reaction by turbidity derived from magnesium pyrophosphate formation. Biochem Biophys Res Commun 289(1): $150-154$.

Notomi T, Okayama H, Masubuchi H, Yonekawa T, Watanabe K, Amino N, Hase T (2000) Loop-mediated isothermal amplification of DNA. Nucleic Acids Res 28(12): E63.

Osako T, Iwase T, Kimura K, Masumura K, Horii R, Akiyama F (2012) Incidence and possible pathogenesis of sentinel node micrometastases in ductal carcinoma in situ of the breast detected using molecular whole lymph node assay. Br J Cancer 106(10): 1675-1681.

Osako T, Iwase T, Kimura K, Yamashita K, Horii R, Akiyama F (2011a) Accurate staging of axillary lymph nodes from breast cancer patients using a novel molecular method. Br J Cancer 105(8): $1197-1202$.

Osako T, Iwase T, Kimura K, Yamashita K, Horii R, Yanagisawa A, Akiyama F (2011b) Intraoperative molecular assay for sentinel lymph node metastases in early stage breast cancer: a comparative analysis between one-step nucleic acid amplification whole node assay and routine frozen section histology. Cancer 117(19): 4365-4374.

Remoundos DD, Ng VV, Wilson HA, Ahmed F, Chia Y, Cunnick GH (2013) The use of one step nucleic-acid amplification (OSNA) in clinical practice: a single-centre study. Breast 22(2): 162-167.

Rouzier R, Extra JM, Klijanienko J, Falcou MC, Asselain B, Vincent-Salomon A, Vielh P, Bourstyn E (2002) Incidence and prognostic significance of complete axillary downstaging after primary chemotherapy in breast cancer patients with T1 to T3 tumors and cytologically proven axillary metastatic lymph nodes. J Clin Oncol 20(5): 1304-1310.

Sahoo S, Lester SC (2009) Pathology of breast carcinomas after neoadjuvant chemotherapy: an overview with recommendations on specimen processing and reporting. Arch Pathol Lab Med 133(4): 633-642.

Sakakibara M, Nagashima T, Kadowaki M, Onai Y, Fujimori T, Yokomizo J, Suzuki H, Fushimi K, Nakatani Y, Miyazaki M (2009) Clinical significance of axillary microresiduals after neoadjuvant chemotherapy in breast cancer patients with cytologically proven metastases. Ann Surg Oncol 16(9): $2470-2478$.

Tamaki Y (2012) One-step nucleic acid amplification assay (OSNA) for sentinel lymph node biopsy. Breast Cancer; e-pub ahead of print 9 August 2012; doi:10.1007/s12282-012-0390-x.

Tsujimoto M, Nakabayashi K, Yoshidome K, Kaneko T, Iwase T, Akiyama F, Kato Y, Tsuda H, Ueda S, Sato K, Tamaki Y, Noguchi S, Kataoka TR, Nakajima H, Komoike Y, Inaji H, Tsugawa K, Suzuki K, Nakamura S, Daitoh M, Otomo Y, Matsuura N (2007) One-step nucleic acid amplification for intraoperative detection of lymph node metastasis in breast cancer patients. Clin Cancer Res 13(16): 4807-4816.

von Minckwitz G, Untch M, Blohmer JU, Costa SD, Eidtmann H, Fasching PA, Gerber B, Eiermann W, Hilfrich J, Huober J, Jackisch C, Kaufmann M, Konecny GE, Denkert C, Nekljudova V, Mehta K, Loibl S (2012) Definition and impact of pathologic complete response on prognosis after neoadjuvant chemotherapy in various intrinsic breast cancer subtypes. J Clin Oncol 30(15): 1796-1804.

This work is published under the standard license to publish agreement. After 12 months the work will become freely available and the license terms will switch to a Creative Commons AttributionNonCommercial-Share Alike 3.0 Unported License. 